\title{
The Profile of Teachers' Performance in Designing Practical Chemistry Laboratory Works
}

\author{
Galuh Yuliani*, Heli Siti Halimatul, Siti Aisyah, Tuszie Widhiyanti \\ Chemistry Department \\ Universitas Pendidikan Indonesia \\ Bandung, Indonesia \\ *galuh@upi.edu
}

\begin{abstract}
In chemistry, laboratory works are ideal media for students to understand the connection between the unseen microscopic world and the observable macroscopic world. Laboratory experiences provide opportunities for team building, inquiry-based learning, hands-on activities, and exposure to standard laboratory equipment and technology. Many of the concepts and principles common in high school chemistry courses can actually be demonstrated or discovered through experiments performed with simple apparatus. Currently, investigations on the Indonesian teachers' performance in designing practical chemistry laboratory are still very rare. The investigation is crucial to understand the problems and challenges faced by Chemistry teachers in preparing laboratory works and to improve their performance based on the research findings. This study investigated the teachers' current practice of laboratory activities in various high schools in West Java, Indonesia. This research is a survey research with a qualitative approach. The research subjects were 27 senior high school. The instrument used in this study was a non-test in the form of a Likert scale questionnaire. The questionnaires consisted of 9 items covering the pre-laboratory activity, during laboratory activity and postlaboratory activity. It was found that the number of experiments conducted, teachers' preparation and the reflection session after laboratory works were considered sufficient. However, the teachers' awareness on the safety instruction and green chemistry approach were still low. Additionally, laboratory works that focuses on the problem-based and discovery are not popular among teachers. It is suggested that the later practical work method is introduced to teachers because this approach allows students to practice higher level analytical skills, problem solving, connection to theory and transferable skills.
\end{abstract}

Keywords: chemistry, teachers, profile, practical, laboratory

\section{INTRODUCTION}

Chemistry has been considered as a laboratory science that requires vigorous laboratory experiences. These include identification, manipulation, and general use of laboratory equipment. Laboratory work is particularly useful for students to acquire manipulative skills and to conduct observations in a critical manner. Simultaneously, the student may gain knowledge of a variety of experimental techniques. The reporting stage as well as the result interpretation and the presentation of scientific work are also crucial for students' skill development. Additionally, the students may take a larger part in designing experiments via some investigational studies or a small research project [1].

Other important part to support practical chemistry works in high school is the laboratory equipment necessary to conduct meaningful demonstrations and experiments [2]. The laboratory environment should be accessible to all students and support students with limited strength or mobility.

Within chemistry curriculum, it is recommended that the teachers develop instruction that is student-centered and emphasizes concrete examples of the concepts. In the studentcentered lessons, the lesson emphasizes more on the students' learning rather than on the teachers' activities and teaching [3].

Ideal laboratory instruction should be student-centered and emphasizes to ensure that students develop essential skills in science. Laboratory exercises should come in three phases: the pre-lab, the lab procedure, and the post-lab. In the pre-lab, students consider the concept or principle to be investigated. They predict and hypothesize. Effective pre-lab questions can prompt students to review and recall previously learned material that is pertinent to the laboratory [4]. In the lab experience, students learn to plan their actions, and to identify and control variables; they observe, measure, classify, and record [5]. The post-lab challenges students to analyze and interpret data, evaluate the effectiveness of the procedure, formulate models, and communicate their findings in written and oral formats. In the post-lab, students can also relate or compare the results and concepts to known phenomena [6].

The important role on practical chemistry and laboratory practice in chemistry learning has been incorporated in national chemistry curriculum [7]. However, the study that investigate how these chemistry teachers conduct the chemical laboratory practice and the efficiencies of the practical works based on the available best practice could not found in the literature [8]. Therefore, this study aims at capturing the profile of teachers' performance in conducting practical chemistry laboratory works. The investigation includes the pre-, during, and postlaboratory activities. 


\section{MethodOLOGY}

This study uses a qualitative approach. Twenty-seven chemistry teachers from West Java areas were selected. A nontest in the form of Likert scale questionnaire was utilized. It contained 8 items covering pre laboratory activity, during laboratory activity and post-laboratory activity.

\section{DISCUSSION}

\section{A. Number of Practical Works in One Semester}

All of the teachers participated in this study mentioned that they already included practical works in their chemistry lessons. The number of practical works held every semester varied from 1 to 5 and above (Fig 1). Almost half of the teachers claimed that they conducted 5 or more practical works in each semester. This number include the demonstrations and hands-on practical laboratory.

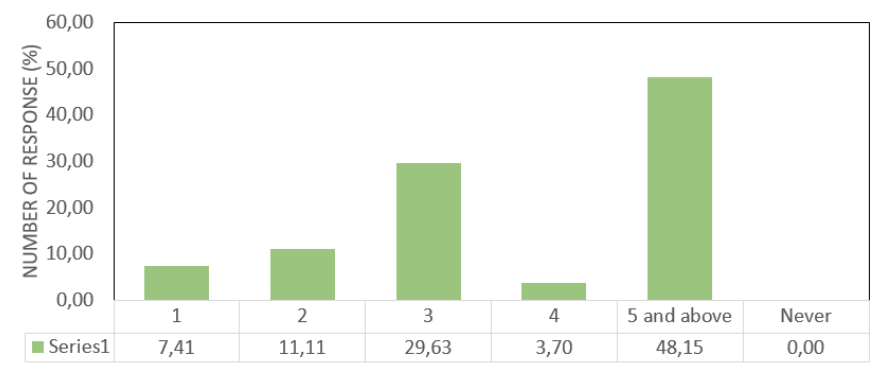

Fig. 1. Number of practical works in one semester.

\section{B. Number of Group and Number of Students in a Group}

The number of students in a class varied depending on the schools, usually from 20-40 students (Fig 2). Most teachers reported that the number of groups in their class during practical sessions are six, in which each groups consisted of 4-5 students. From the literature, it was known that number of students ideally existed in one group sharing common laboratory equipment is 2-3. This suggests that the number of students in one group are still too many to ensure that each student has ample time and opportunity to manipulate and explore equipment and experiment [9].

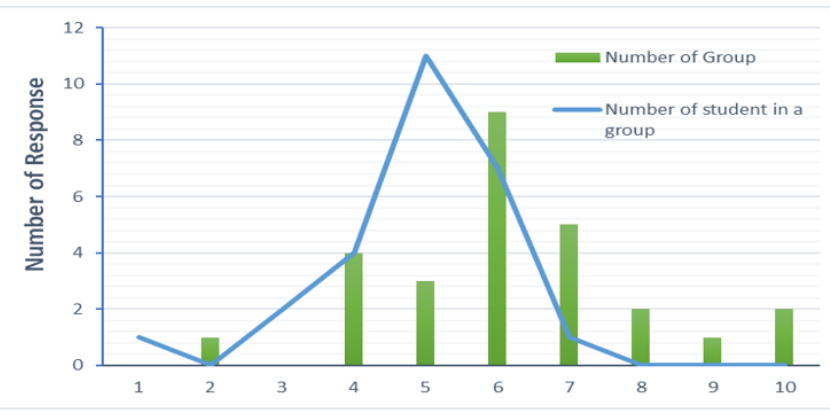

Fig. 2. Number of group and number of students in a group.

\section{Teachers' Preparation before Practical Work}

All of the teachers participating in this study reported that they always prepare the laboratory instruction and the material and equipment needed prior to practical work (Fig 3). However, less than $50 \%$ of the teachers consult to the MSDS to check whether their procedure is safe to students. This is quite worrying since safety and health occupation is crucial, especially to secondary students that are not well trained in using some laboratory equipment.

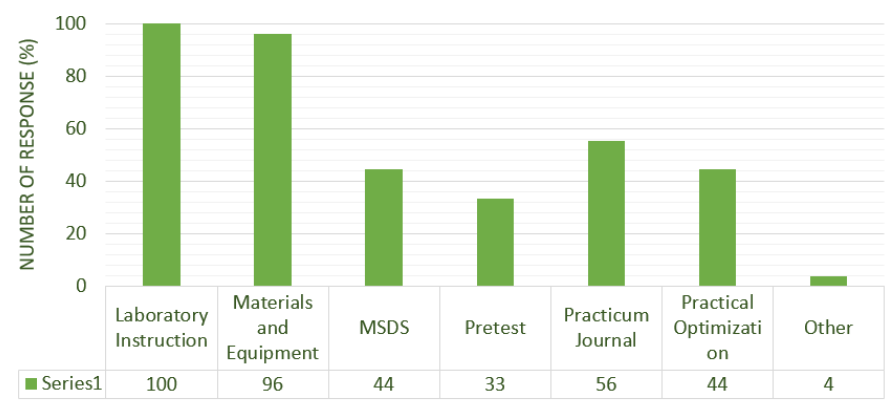

Fig. 3. Teacher's preparation before practical work.

\section{Students' Preparation}

The students' preparation commonly conducted comprised of preparing materials, equipment and practicum journal (Fig 4). Again, it is not mandatory for the students to see the MSDS prior to practical work. It is actually important to foster students' awareness on safety and hazard of materials they used during practical work by asking them to study the material safety data sheet (MSDS).

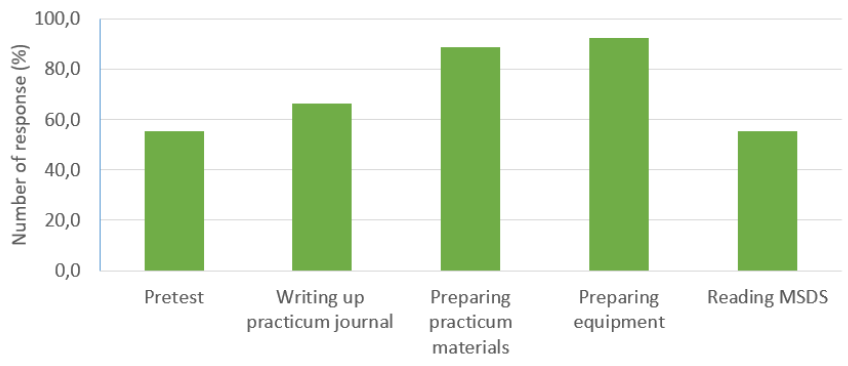

Fig. 4. Students' preparation.

\section{E. Laboratory Instruction Style}

According to Domin, there are 4 laboratory instructional styles, namely expository, inquiry, discovery and problem based. These styles are classified based on the approach (deductive or inductive), types of procedure (given or student generated) and outcome (predetermined or undetermined) [10].

Based on the questionnaires, the most common instruction style adopted by teachers are demonstration, direct observation and practice the laboratory skills (Fig 5). All of these styles belong to the expository style, which is also known as traditional style, deductive or cook-book. This style relies 
mostly on laboratory manuals where students only perform the experiment by following prescribed procedures with predetermined outcome.

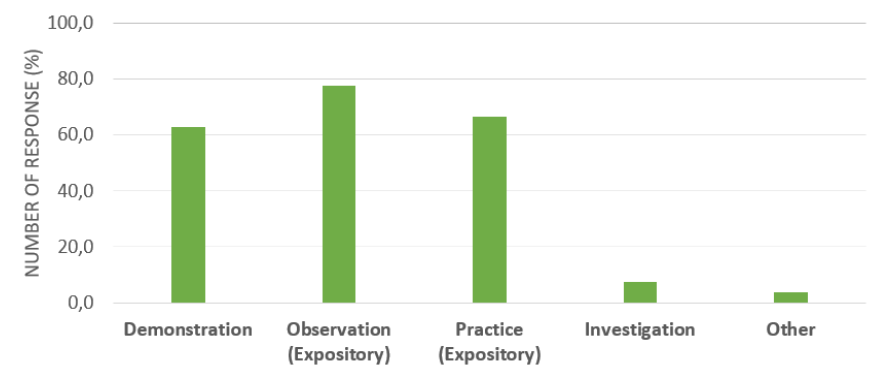

Fig. 5. Laboratory instruction style.

\section{F. Challenges in Conducting Laboratory Work in Chemistry}

Teachers reported that time allocation, equipment and development of practicum instruction are among the most prominent challenges in conduction laboratory works (Fig 6). Time allocation is particularly the biggest problem that needs to be addressed when designing a practical work. The short time allocation (usually less than $2 \mathrm{~h}$ ) is considered insufficient to develop a laboratory style requiring students' internalization and analysis, such as discovery or problem based. This suggest that chemistry or science lesson in school should specifically allocated practical work every week with longer time allocation in order to facilitate the development of a fruitful and efficient laboratory manual and ensure its implementation in chemistry lesson [11].

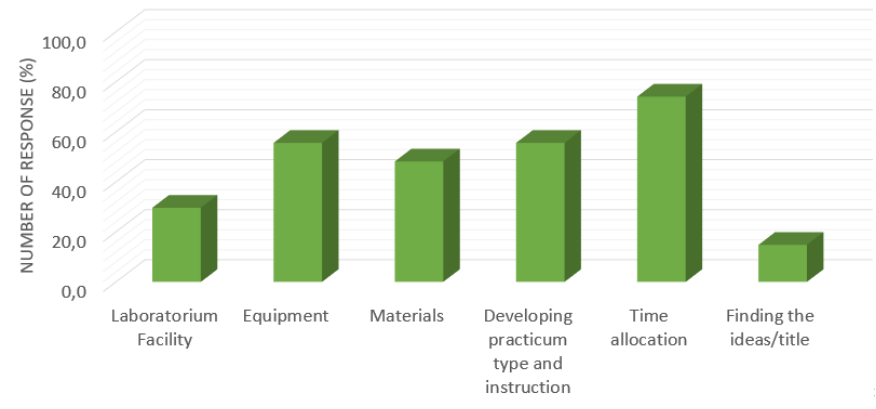

Fig. 6. Challenges in conducting laboratory work in Chemistry lesson.

\section{G. Post-laboratory Activity}

Almost $100 \%$ of teachers reported that they conducted post laboratory session to ensure that students' received clear comprehension on the subject material that were introduced in laboratory activity (Fig 7). The post laboratory activities include reflection and discussion sessions after laboratory work and occasionally followed with student assignment to writing up a report either individually and/or within a group.

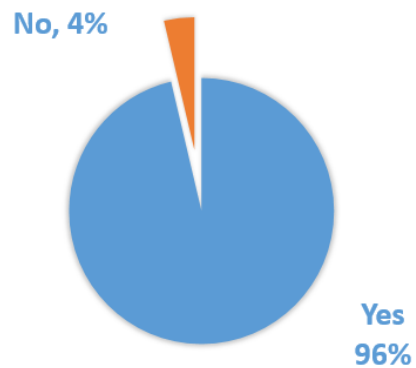

(a)

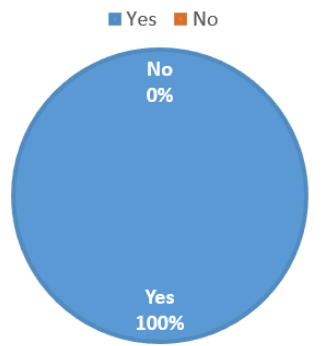

(b)
Fig. 7. Post laboratory activity: (a) practical report (b) reflection and discussion sessions.

\section{CONCLUSION}

According to the data analysis and research findings, it can be concluded:

- In terms of number of experiment conducted in one semester, most of the teachers conducted at least 3 experiments in one semester. However, above $80 \%$ of the experiments still employed expository types.

- Only half of the teachers considered the MSDS manual analysis as one of the important step in preparing the practical works

- The perceived challenges for conducting an experiment were time allocation, equipment and development of practical instruction

- In terms of students group, the number of students in a group was still considered un-ideal in conducting effective practical works

- Almost all of the teachers have included the post laboratory works, such as report writing and reflection/discussion as crucial stages in conducting practical works

\section{ACKNOWLEDGMENT}

The authors thank Universitas Pendidikan Indonesia for research funding under the Pengabdian Kepada Masyarakat Bidang Ilmu scheme and the School of Postgraduate Studies for support in attending the Asian Education Symposium.

\section{REFERENCES}

[1] A. Hofstein, "The Laboratory in Chemistry Education: Thirty Years of Experience With Developments, Implementation, and Research". Chem. Educ. Res. Pract., 5(3), 247-264. 2004.

[2] E. McKee, V.M. Williamson, and L.E. Ruebush, "Effects of a demonstration laboratory on student learning". Journal of Science Education and Technology, 16(5), 395-400. 2007.

[3] X. Meng, L. Yang, H. Sun, X. Du, and B. Yang, "A Novel Studentcentered Teaching Method STQD Using Multiple Teaching Methodologies to Improve Students' Learning in Pharmacy Education". American Journal of Pharmaceutical Education, 83(2), ajpe6505. 2017. 
[4] H.Y. Agustian and M.K. Seery, "Reasserting the role of pre-laboratory activities in chemistry education: A proposed framework for their design". Chemistry Education Research and Practice, 18(4), 518-532. 2017.

[5] A. Hofstein and V.N. Lunetta, "The Role of the Laboratory in Science Teaching: Neglected Aspects of Research". Review of Educational Research, 52(2), 201-217. 1982.

[6] Y.A. Tenaw, Effective strategies for teaching chemistry. International Journal of Education Research and Reviews, 3(3), 78-84. 2015.

[7] M. Stojanovska and V. Petrusevski, Practical Work in Chemistry, its goals and effects., (November). 2015.
[8] J. Copriady, "Practical Implementation of Practical Chemistry among Scondary School Teachers". Asian Journal of Sciencetific Research, 8(1), 22-40. 2015.

[9] H.M. Fadzil and R.M. Saat, "Exploring students' acquisition of manipulative skills during science practical work". Eurasia Journal of Mathematics, Science and Technology Education, 13(8), 4591-4607. 2017.

[10] D.S. Domin, "Students' perceptions of when conceptual development occurs during laboratory instruction". Chemistry Education Research and Practice, 8(2), 140-152. 2007.

[11] R. Millar and I. Abrahams, "Practical work - Research Database, The University of York”. School Science Review, 91(334), vol 91, no. 334, pp. 59-64. 2009. 2 